\title{
Analisis Intention Transaction Pada Usaha Mikro Kecil dan Menengah (UMKM) Berbasis E-Commerce di Kota Padang
}

\author{
Sepris Yonaldi ${ }^{1}$, Ilham Agustin Darma ${ }^{2}$ \\ 1,2 Fakultas Ekonomi Universitas Tamansiswa Padang
}

\begin{abstract}
SMEs in the city of Padang lack effectiveness and efficiency in the sales process due to the low use of ecommerce technology. In addition, there is a lack of information for SME players about the effect of ecommerce adoption in increasing competitiveness and performance for the development of more advanced SMEs in the future. The objectives of this study were: to determine the effect of perceived risk and perceived enjoyment on intention transactions in public using e-commerce in Padang city, to determine the effect of perceived risk through perceived enjoyment on intention transactions, and to determine the effect of perceived enjoyment through perceived risk on an intention transaction. This research uses quantitative methods with an explanatory approach. Field surveys were also carried out to obtain primary data from SMEs in the city of Padang that have used e-commerce to run their businesses. The results of this research are: a) The variable perceived risk has no effect on the intention of transactions on e-commerce-based SMEs in the city of Padang, b) The variable perceived enjoyment has no effect on the intention of transactions on e-commerce-based SMEs in the city of Padang, c) The variable perceived enjoyment through perceived enjoyment on intention transactions does not have a significant effect on intention transactions, d) The variable perceived enjoyment through perceived enjoyment on intention transactions has no significant effect on intention transactions.
\end{abstract}

\begin{abstract}
Abstrak
UMKM yang ada di kota Padang kurang efektivitas dan efisiensi dalam proses penjulan yang disebabkan masih rendahnya penggunaan teknologi e-commerce. Selain itu kurangnya informasi bagi pelaku UMKM tentang pengaruh adopsi e-commerce dalam peningkatan daya saing dan kinerja untuk pengembangan UMKM yang lebih maju di masa yang akan datang. Tujuan penelitian ini adalah: untuk mengetahui pengaruh perceived of risk dan perceived enjoyment terhadapintention transaction pada umkm yang menggunakan e-commerce di kota padang, untuk mengetahui pengaruh perceived of risk melalui perceived enjoyment terhadap intention transaction, dan untuk mngetahui pengaruh perceived enjoyment melalui perceived of risk terhadap intention transaction. Penelitian ini menggunakan metode kuantitatif dengan pendekatan explanatory. Survey ke lapangan juga dilakukan untuk mendapatkan data primer dari UMKM yang berada di kota Padang yang sudah menggunakan e-commerce untuk menjalankan bisnisnya. Hasil peneitian ini adalah: a) Variabel perceived of risk, tidak berpengaruh terhadap intention transaction pada UMKM berbasis e-commerce di kota Padang, b) Variabel perceived enjoyment tidak berpengaruh terhadap intention transaction pada UMKM berbasis e-commerce di kota Padang, c) Variabel perceived of risk melalui perceived enjoyment terhadap intention transaction tidak berpengaruh signifikan terhadap intention transaction, d) Variabel perceived enjoyment melalui perceivd of risk terhadap intention transaction tidak berpengaruh signifikan terhadap intention transaction.
\end{abstract}

Keywords: e-commerce, UMKM, perceived enjoyment, perceived of risk, intention transaction

Corresponding author: Sepris Yonaldi (seprisyonaldi@gmail.com) 


\section{Pendahuluan}

Teknologi yang terus berkembang dari waktu kewaktu memberikan dampak besar terhadap segala aspek kehidupan, baik dampak positif maupun negatif. Dampak positif terutama terlihat di bidang bisnis dan ekonomi. Teknologi informasi misalnya telah mengubah cara dan peta bisnis dunia. Hal ini terlihat pada penggunaan teknologi informasi oleh para pebisnis untuk mempromosikan jasa dan produknya melalui website, mailling list maupun dengan menggunakan chat atau pesan singkat. Dampak negatif perkembangan teknologi di antaranya kehilangan kemampuan berbaur dengan masyarakatdan cenderung nyaman dengan kehidupan online, kejahatan internet tanpa mengenal batas dan teritorial yang bisa datang kapan saja, dan masih banyak lagi (Ratnaya, 2011). Perkembangan teknologi menuntut pebisnis untuk aktif dan menguasai teknologi tersebut agar tidak gagap teknologi. Salah satu bentuk teknologi informasi yang banyak digunakan pebisnis saat ini adalah dengan mengadops ie-commerce pada usaha yang mereka jalani.

Salah satu hal mendasar yang membedakan e-commerce dengan pasar tradisional adalah pemanfaatan jaringan internet. Jaringan internet di Indonesia bukanlah hal yang baru karena semua orang mengenal dengan baik jaringan internet itu sendiri. Penggunaan internet di Indonesia dapat dilihat pada Gambar 1. Jaringan bukan hanya digunakan untuk mencari informasi, tetapi juga untuk melakukan pemasaran berupa jual beli barang baik yang diproduksi oleh pabrik maupun home industry dan jasa.

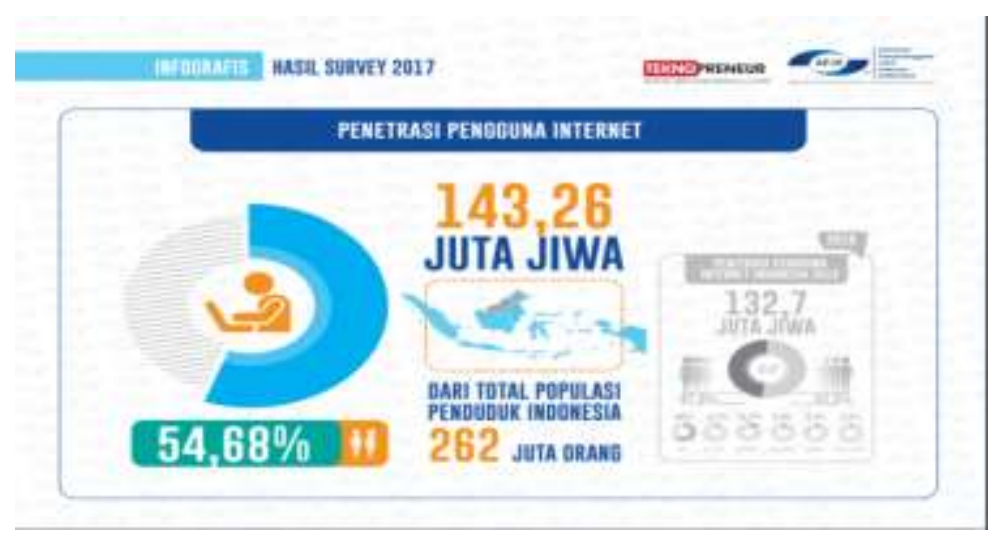

Gambar 1. Pertumbuhan penggunaan internet di Indonesia tahun 2017

(APJII, 2017)

Berdasarkan data di atas dari 262 juta jiwa penduduk Indonesia, sekitar 143,26 juta jiwa menggunakan internet. Berarti sekitar 54,68\% atau sebagian dari penduduk Indonesia telah menggunakan jaringan internet. Jumlah tersebut meningkat jika dibandingkan dengan tahun 2016 yang hanya sebesar 132,7 juta jiwa dan akan terus meningkat. 
Usaha Mikro, Kecil, dan Menengah (UMKM) adalah salah satu bidang yang memberikan kontribusi signifikan dan dapat memacu pertumbuhan ekonomi Indonesia. Pemerintah telah mengatur dalam UndangUndang tentang UMKM, yaitu UU RI No. 20 tahun 2008 yang menyatakan bahwa Usaha Mikro, Kecil, dan Menengah bertujuan menumbuhkan dan mengembangkan usahanya dalam rangka membangun perekonomian nasional berdasarkan demokrasi ekonomi yang berkeadilan. Melihat hal tersebut telah banyak orang yang beralih profesi menjadi pengusaha kecil karena melihat peluang yang ada.

Kelompok usaha ini sering dikaitkan dengan keadaan ekonomi sosial masyarakat di dunia. Keadaan yang juga dialami oleh bangsa Indonesia seperti kemiskinan, jumlah pengangguran yang sangat tinggi, tingkat pendidikan yang rendah, krisis utang luar negeri, ketimpangan distribusi pendapatan, serta berbagai aspek negatif lainnya, termasuk masalah urbanisasi dan defisit neraca pembayaran (Yonaldi :2018).

Pertumbuhan UMKM sendiri dimulai sejak krisis moneter pada tahun 1998. Berdasarkan data Badan Statistik Nasional pada tahun 2012, jumlah UMKM yang ada di Indonesia mendekati 99,99\% dengan jumlah tenaga kerja yang terlibat mencapai $97,16 \%$ terhadap jumlah tenaga kerja Indonesia. Pada tahun 2012 jumlah UMKM yang ada di Indonesia mencapai 55,2 juta unit dengan tingkat serapan tenaga kerja 3 5 tenaga kerja pada masing-masing UMKM (BPS, 2012). Melihat angka tersebut pemerintah berharap dapat mengurangi tingkat pengangguran 1-2\%.Provinsi Sumatera Barat juga memilik jumlah UMKM yang cukup banyak, salah satunya di kota Padang yang telah mendapat tanda kehormatan satya lencana pembangunan UMKM oleh Wakil Presiden Repubik Indonesia. Data UMKM di kota Padang dapat dilihat pada Tabel 1.

Tabel 1 Data UMKM di kota Padang tahun 2014-2017

\begin{tabular}{lcccc}
\hline \multicolumn{1}{c}{ Kecamatan } & \multicolumn{4}{c}{ Jumlah UMKM } \\
\cline { 2 - 5 } & $\mathbf{2 0 1 4}$ & $\mathbf{2 0 1 5}$ & $\mathbf{2 0 1 6}$ & $\mathbf{2 0 1 7}$ \\
\hline Padang Barat & 9.229 & 9.429 & 9.629 & 9.929 \\
\hline Padang Timur & 5.352 & 5.552 & 5.752 & 6.022 \\
\hline Padang Selatan & 5.813 & 6.053 & 6.288 & 6.618 \\
\hline Koto Tangah & 6.824 & 7.06 & 7.3 & 7.66 \\
\hline Lubuk Begalung & 7.002 & 7.357 & 7.657 & 8.077 \\
\hline Pauh & 3.492 & 3.672 & 3.853 & 4.122 \\
\hline Lubuk Kilangan & 6.334 & 6.474 & 6.614 & 6.824 \\
\hline Kuranji & 12.169 & 12.349 & 12.529 & 12.799 \\
\hline Padang Utara & 5.395 & 5.535 & 5.675 & 5.885 \\
\hline Nanggalo & 7.351 & 7.471 & 7.591 & 7.725 \\
\hline Bungus T. Kabung & 5.201 & 5.221 & 5.341 & 5.521 \\
\hline \multicolumn{1}{c}{ Total } & $\mathbf{7 4 . 0 6 2}$ & $\mathbf{7 6 . 1 7 3}$ & $\mathbf{7 8 . 2 2 9}$ & $\mathbf{8 1 . 1 8 2}$ \\
\hline Sul
\end{tabular}

Sumber: BPS, 2018 
Dari tabel di atas terlihat bahwa jumlah UMKM di Kota Padang per kecamatan selalu mengalami peningkatan setiap tahun, hingga pada tahun 2017 jumlah UMKM sudah mencapai 81.182 unit usaha. Dari 11 kecamatan, jumlah UMKM terbanyak di kota Padang berada di kecamatan Kuranji dengan jumlah lebih dari 12.000 unit usaha dan paling sedikit terdapat di kecamatan Pauh dengan jumlah hanya 4.122.

Berdasarkan uraian di atas, peneliti tertarik untuk mengangkat masalah tersebut pada UMKM di kota Padang. Alasan dalam pemilihan UMKM yang ada di kota Padang, karena masih kurangnya efektivitas dan efisiensi proses penjulan di kota ini yang disebabkan masih rendahnya penggunaan teknologi e-commerce di kota Padang. Selain itu kurangnya informasi bagi pelaku UMKM tentang pengaruh adopsi e-commerce dalam peningkatan daya saing dan kinerja untuk pengembangan UMKM yang lebih maju di masa yang akan datang.

\section{Literatur Review dan Pengembangan Hipotesis}

\section{Literatur Review}

E-commerce (Electronic commerce) menurut McLeod \& Schell (2008) adalah penggunaan internet untuk aktivitastransaksibisnis yang dalam beberapa tahun terakhir telah berkembang signifikan. Hal ini karena e-commerce berperan sebagai salah satu teknologi informasi yang memungkinkan perusahaan dapat mengakses pasar global secara cepat, tepat, dan efisien. Kotler \&Amstrong (dalam Bhakti, 2009) mendefinisikan e-commerce sebagai saluran yang dapat dijangkau seseorang melalui komputer atau modem. Bahasa lainnya, e-commerce merupakan saluran online yang digunakan oleh pelaku bisnis untuk melakukan kegiatan atau aktivitas bisnisnya dan digunakan oleh konsumen sebagai tempat untuk mendapatkan informasi tentang produk yang diinginkan. Prosesnya diawali dengan pemberian jasa informasi pada konsumen oleh produsen dalam menentukan pilihan menggunakan bantuan komputer dan modem.

Turban (2010) mengatakan, bahwa pada generasi pertama dari e-commerce hanya fokus untuk aktivitas organisasi dan proses bisnis, namun sekarang e-commerce mencakup semua jejaring sosial atau yang dikenal dengan media sosial.

"Reality today e-commerce not only as a supporting instrument, but its existence is transformed into a lifestyle (e-lifestyle) in buying andselling transactions without any limitations of space and time" (Yonaldi, 2018). 
UMKM juga telah beralih dari konvensional menjadi e-commerce. Menurut Yonaldi (2018:94-97), faktorfaktor yang mempengaruhi UMKM konvensional bertransformasi menggunakan e-commerce sebagai model bisnis, yaitu:

1) Konsumen milenial. Konsumen merupakan stakeholders utama bagi produsen, tanpa konsumen, produsen (bisnis) tersebut tidak ada nilainya (costumer is profit). Hal ini menjelaskan bahwa apapun yang menjadi keinginan konsumen harus bisa dipenuhi oleh produsen. Beberapa indikator konsumen milenial, antara lain : Teknologi digital sebagai kebutuhan dasar, belanja online sebagai gaya hidup, kecepatan bertransaksi, kenyamanan dalam transaksi.

2) Promosi berbasis jaringan internet (e-promotion). Promosi merupakan bagian dari kegiatan utama pemasaran yang harus dilakukan oleh sebuah perusahaan. Tanpa adanya strategi promosi yang tepat, maka barang atau jasa yang ditawarkan oleh konsumen tidak akan bisa dikenali oleh para calon konsumen. Dalam kegiatan promosi konvensional (non-ecommerce), ada kegiatan promosi yang lazim dilakukan, seperti promosi dalam periklanan, promosi publik, promosi secara langsung, promosi perorangan, serta promosi dari mulut ke mulut konsumen.

Ada dua poin penting dalam definisi persepsi risiko, yaitu ketidakpastian dan konsekuensi. Definisi ini menekankan bahwa konsumen dipengaruhi oleh risiko yang mereka persepsikan, tanpa mempedulikan apakah sebenarnya risiko itu ada atau tidak. Risiko yang tidak ada dalam persepsi konsumen tidak akan mempengaruhi perilaku konsumen (Schiffman \&Kanuk, 2010). Ada beberapa tipe risiko,yaitu Physical Risk, Performance Risk, Psychological Risk, Financial Risk, Time-Loss Risk, and Social Risk (Schiffman \& Kanuk, 2010; Hoyer et al., 2013).

Perceived enjoyment dapat dikatakan sebagai suatu kondisi kegiatan untuk menggunakan sistem tertentu yang dianggap menyenangkan dalam dirinya sendiri, selain dari setiap konsekuensi kinerja yang dihasilkan dari penggunaan sistem. Enjoyment didefenisikan sebagai suatu kesadaran dari sensasi secara holistic, ketika orang secara total terlibat dalam aktivitas tertentu. Jadi, perceived enjoyment adalah bagian dari belief variabel yang merupakan tiga persepsi penggunaan tentang karakteristik sistem (Gahtani \& King, 1999).

Penelitian ini menggunakan metode kuantitatif dengan pendekatan explanatory, yaitu dengan tujuan mengungkapkan secara luas dan mendalam tentang sebab dan hal yang mempengaruhi terjadinya sesuatu. Survey ke lapangan juga dilakukan untuk mendapatkan data primer dari UMKM yang berada di kota Padang yang sudah menggunakan e-commerce untuk menjalankan bisnisnya. 


\section{Hipotesis}

1. Diduga ada pengaruh perceived of risk terhadapintention transaction pada UMKM yang menggunakan e-commerce di kota Padang $\left(\mathrm{H}_{1}\right)$

2. Diduga ada pengaruh perceived enjoyment terhadap intention transaction pada UMKM yang menggunakan e-commerce di kota Padang $\left(\mathrm{H}_{2}\right)$

3. Diduga ada Pengaruh Perceived of Risk Melalui Perceived Enjoyment Terhadap Intention Transaction $\left(\mathrm{H}_{3}\right)$.

4. Diduga ada Pengaruh Perceived Enjoyment Melalui Perceived of Risk Terhadap Intention Transaction $\left(\mathrm{H}_{4}\right)$

\section{MetodeRiset}

Penelitian ini menggunakan metode kuantitatif dengan pendekatan explanatory, yaitu dengan tujuan mengungkapkan secara luas dan mendalam tentang sebab dan hal yang mempengaruhi terjadinya sesuatu. Survey ke lapangan juga dilakukan untuk mendapatkan data primer dari UMKM yang berada di kota Padang yang sudah menggunakan e-commerce untuk menjalankan bisnisnya.

\section{Hasil dan Analisis}

\section{Hasil Penelitian}

Berdasarkan penelitian yang telah dilakukan dengan melihat beberapa aspek yang berpengaruh terhadap intention transaction maka diperoleh hasil sebagai berikut;

\section{Pengaruh Variabel Perceived of Risk Terhadap Intention Transaction $\left(\mathrm{H}_{1}\right)$}

Variabel perceived of risk $\left(\mathrm{X}_{1}\right)$ tidak berpengaruh terhadap intention transaction pada UMKM berbasis e-Commerce di kota Padang. Hal ini dapat dilihat dari signifikan 0,168 $>0,05$, dan nilai $\mathrm{t}_{\text {Tabel }} \mathrm{df}=\mathrm{n}-$ $\mathrm{k}=100-3(1,660)$ berarti nilai $\mathrm{t}_{\text {hitung }}<\mathrm{t}_{\text {Tabel }}(1,387<1,660)$, maka hipotesis $\mathrm{H}_{1}$, bahwa perceived of risk tidak berpengaruh signifikan terhadap intention transactionsehingga $\mathrm{H}_{0}$ diterima dan $\mathrm{H}_{\mathrm{a}}$ ditolak.

\section{Pengaruh Variabel Perceived Enjoyment Terhadap Intention Transaction $\left(\mathrm{H}_{2}\right)$}

Variabel perceived enjoyment tidak berpengaruh terhadap intention transaction pada UMKM berbasis e-Commerce di kota Padang. Hal ini dapat dilihat dari signifikan 0,788 $>0,05$. Dengan $\mathrm{df}=\mathrm{n}-\mathrm{k}=$ $100-3=97(1,660)$ berarti nilai $\mathrm{t}_{\text {hitung }}<\mathrm{t}_{\text {Tabel }}(-0,269<1,660) . \mathrm{MakaH}_{2}$, perceived enjoyment tidak berpengaruh signifikan terhadap intention transaction sehingga $\mathrm{H}_{0}$ diterima dan $\mathrm{H}_{2}$ ditolak.

\section{Pengaruh Perceived of Risk Melalui Perceived Enjoyment Terhadap Intention Transaction ( $\left.\mathrm{H}_{3}\right)$}


Nilai $t_{\text {hitung }}$ untuk variabel perceived of risk melalui perceivd enjoyment terhadap intention transaction adalah 1,294 dengan probabiliti signifikan 0,199. Nilai df $=\mathrm{n}-\mathrm{k}=100-3=97$ diperoleh sebesar 1,660 , dengan hasil tesebut bahwa $t_{\text {hitung }}>t_{\text {Tabel }}(1,294<1,660)$ dan nilai signifikan $0,199>0,05$ maka hipotesis $\mathrm{H}_{3}$, perceived of risk melalui perceived Enjoyment tidak berpengaruh signifikan terhadap intention transaction sehingga $\mathrm{H}_{0}$ diterima dan $\mathrm{H}_{3}$ ditolak.

\section{Pengaruh Perceived Enjoyment Melalui Perceived of Risk Terhadap Intention Transaction $\left(\mathrm{H}_{4}\right)$}

Nilai $t_{\text {hitung }}$ untuk variabel perceived enjoyment melalui perceivd of risk terhadap intention transaction adalah 1,294 dengan probabiliti signifikan 0,199. Nilai $\mathrm{df}=\mathrm{n}-\mathrm{k}=100-3=97$ diperoleh sebesar 1,660 dengan hasil tersebut bahwa $\mathrm{t}_{\text {hitung }}<\mathrm{t}_{\text {Tabel }}(1,294<1,660)$ dan nilai signifikan 0,199>0,05, maka variabel perceived of risk enjoyment melalui perceived of risk tidak berpengaruh signifikan terhadap intention transaction. Jadi hipotesis $\mathrm{H}_{3}$, perceived enjoyment melalui perceived of risk terhadap intention transaction sehingga $\mathrm{H}_{0}$ diterima dan $\mathrm{H}_{3}$ ditolak.

\section{Analisis}

Dari penelitian yang sudah dilakukan diketahui bahwa implikasi pada penelitian ini adalah tidak terdapat pengaruh yang signifikan secara parsial pada setiap variabel yang diteliti, yaitu perceived of risk, perceived enjoyment dan intention transaction pada UMKM berbasis e-commerce di kota Padang.Variabel perceived of risk tidak berpengaruh terhadap intention transaction pada UMKM.

Dampak dari perceived of risk tidak dirasakan oleh pelaku usaha ketika bertransaksi menggunakan $e$ commerce. Berdasarkan hasil penelitian ini para pelaku usaha lebih meningkatkan lagi penggunaan media online dalam melakukan transaksi. Hasil pencapaian $79,53 \%$ dikatakan cukup sesuai dengan kategori pencapaian responden sehingga para pelaku harus lebih meningkatkan penggunaan e-commerce dalam kegiatan usahanya.

Variabel perceived enjoyment terhadap intention transaction tidak berpengaruh secara signifikan terhadap intention transaction UMKM. Jika dilihat dari para pelaku usaha yang menggunakan $e$-commerce tidak memberikan dampak kesenangan atau kenikmatan yang dirasakan ketika menggunakan e-commerce dalam berbisnis atau menjalankan usaha setiap hari.

Intensitas transaksi (intention transaction) didefinisikan sebagai kecenderungan hasrat dan minat konsumen dalam menggunakan internet untuk bertransaksi (Lui \& Jamieson, 2003). Indikatornya ada tiga, yaitu:

a) Konsumen memiliki akses pada sistem internet sehingga konsumen menggunakannya. 
b) Jika memiliki akses maka konsumen akan mempertimbangkan untuk menggunakan internet dalam bertransaksi.

c) Konsumen akan bertransaksi menggunakan internet dalam waktu dekat

Ada beberapa indikator menurut Gahtani \& King (1999) dari perceived enjoyment yaitu:

a) Menggunakan e-commerce dalam bekerja membuat saya merasa nyaman.

b) Proses aktual dari penggunaan e-commerce menyenangkan buat saya.

c) Saya senang menggunakan e-commerce.

Variabel perceived of risk melalui perceived enjoyment tidak berpengaruh terhadap intenstion transaction sehingga pelaku usaha tidak merasakan adanya resiko dari kenyamanan yang diberikan dalam berbisnis menggunakan e-commerce. Selain itu, perceived enjoyment melalui perceived of risk tidak berpengaruh, artinya bahwa dalam penggunaan $e$-commerce tidak memberikan kenyamanan dalam penggunaannya untuk berbisnis.

\section{Kesimpulan}

Kesimpulan yang diperoleh berdasarkan penelitian yang telah dilakukan adalah: a) Variabel perceived of risk $\left(\mathrm{X}_{1}\right)$, tidak berpengaruh terhadap intention transaction pada UMKM berbasis e-commerce di kota Padang, b) Variabel perceived enjoyment tidak berpengaruh terhadap intention transaction pada UMKM berbasis e-commerce di kota Padang, c) Variabel perceived of risk melalui perceived enjoyment terhadap intention transaction tidak berpengaruh signifikan terhadap intention transaction, d) Variabel perceived enjoyment melalui perceivd of risk terhadap intention transaction tidak berpengaruh signifikan terhadap intention transaction.

Saran dari hasil penelitian ini adalah: a) Melakukan sosialisasi mengenai Peraturan Pemerintah (PP) No. 46 tahun 2013 kepada para pelaku UMKM agar mereka bisa mengetahui, memahami, dan menjalankan PP tersebut. b) Disarankan kepada Dinas Koperasi dan UMKM Kota Padang untuk meningkatkan intensitas pendidikan dan pelatihan kewirausahaan bagi pelaku UMKM dengan membuat jadwal khusus di setiap kecamatan dan kelurahan. c) Perlunya kerjasama antara Dinas Koperasi dan UMKM dengan pasar modern yang ada di kota Padang untuk memberikan ruang bagi pelaku UMKM dapat ikut memasarkan hasil produksinya di pasar modern tersebut dengan biaya sewa yang terjangkau. 


\section{Daftar Pustaka}

[APJII]Asosiasi Penyelenggara Jasa Internet Indonesi. 2017. Hasil Survei Penetrasi dan Perilaku Pengguna Internet Indonesia 2017.

Kotler, Phillip, Amstrong G. 2012. Prinsip-Prinsip Pemasaran. Edisi 13. Jakarta: Erlangga.

Lui, H.K., Jamieson, R. 2003. "TRiTAM: A Model for Integrating Trust and Risk Perceptions in Business to Consumer E-commerce". 16th Bled E-commerceConference Transformation Bled. Slovenia, June : 349-364.

McLeod, R. dan Schell, Jr., G. P. 2008.Management Information System, Edisi 10, Jakarta: Salemba Empat. Penelitian BPS tahun. 2012. Tentang Penyerapan Tenaga Kerja Oleh UKM

Ratnaya, IG. 2011. "Dampak Negatif Perkembangan Teknologi Informatika dan Komunikasi dan Cara Antisipasinya". Jurnal Pendidikan Teknologi dan Kejuruan 8 (1): 17-28

Yonaldi, S dan Hafrizal O. A. P, M. Fauzan. 2018. E-Commerce Use on Micro, Small and Medium Enterprises (Case study: SMEs at Padang City of Indonesia). Padang: Universitas Tamansiswa Padang.

Yonaldi, Sepris. 2018. Kewirausahaan Bagi Industri Kecil Menengah Di Kota Padang Dalam Rangka Peningkatan Kemampuan Manajemen Dan Perluasan Pasar. Padang: Universitas Tamansiswa Padang.

Yonaldi, Sepris. 2018. Kewirausahaan, Menumbuhkembangkan UMKM di Era Digital. Padang: PT. Brain Insight Indonesia (BRIGHT) 